\title{
Gender susceptibility to COVID-19: a review of the putative role of sex hormones and $\mathrm{X}$ chromosome
}

\author{
C. Foresta ${ }^{1}$ (1) $\cdot$ M. S. Rocca' ${ }^{1}$ A. Di Nisio ${ }^{1}$
}

Received: 9 June 2020 / Accepted: 31 July 2020 / Published online: 16 September 2020

(c) The Author(s) 2020

\begin{abstract}
Background The recent emergence of COVID-19 poses a global health emergency. One of the most frequently reported data is sex-related severity and mortality: according to the last available analysis on 239,709 patients in Italy, lethality is $17.7 \%$ in men and $10.8 \%$ in women, with $59 \%$ of total deaths being men. Interestingly, the infection rate is lower in males than in females, with $45.8 \%$ and $54.2 \%$ of positive cases, respectively, suggesting that gender-related factor may worsen disease evolution. A tentative hypothesis to explain these findings is the role of angiotensin-converting enzyme 2 (ACE2) and serine protease TMPRSS2 involved in viral infection.

Purpose In this review, we summarize the available evidence pointing to gender-related differences in ACE2 and TMPRSS2 expression, from both genetic and endocrine points of view.

Results Altogether, available evidence points toward two not-mutually exclusive mechanisms in gender susceptibility to COVID-19 by sex hormonal regulation of ACE2 and TMPRSS2. On one hand, ACE2 expression could be increased in women, either by estrogens or constitutively by X chromosome inactivation escape or by reduced methylation, providing a larger reservoir of ACE2 to maintain the fundamental equilibrium of RAS regulatory axis. On the other, low levels of androgens in women may keep at low levels TMPRSS2 expression, representing a further protective factor for the development of COVID-19 infection, despite the increased expression of ACE2, which represents the Trojan horse for SARS-CoV-2 entry. Conclusions Both mechanisms consistently point to the role of sex hormones and sex chromosomes in the differential severity and lethality of COVID-19 in men and women.
\end{abstract}

Keywords COVID-19 - ACE2 $\cdot$ TMPRSS2

The recent emergence of the novel, severe acute respiratory syndrome coronavirus (SARS-CoV-2) infection disease (COVID-19) in China and its rapid national and international spread pose a global health emergency. Clinical manifestation of COVID-19 greatly differs by age, sex and other comorbidities. In approximately $20 \%$ of cases, the disease evolves into a severe manifestation that requires hospitalization, intubation and may lead to death in up to $10 \%$ of patients with other comorbidities. One of the most frequently reported epidemiologic data is sex-related COVID-19 mortality: several studies have reported a significant difference in the rate of severe cases between adult

C. Foresta

carlo.foresta@unipd.it

1 Department of Medicine, Unit of Andrology and Medicine of Human Reproduction, University of Padova, Via Giustiniani, 2, 35128 Padua, Italy females and adult males (42\% vs 58\%) [1]. Italy was one of the countries suffering with over 200,000 assessed cases and more than 33,000 deaths [2], with a mortality rate even higher than the one reported in China (14\%). According to the last available sex-related analysis from Italian "Istituto Superiore di Sanità" (ISS) on 239,709 patients, lethality in Italy is $17.7 \%$ in men and $10.8 \%$ in women, with $59 \%$ of total deaths being men (Fig. 1). Interestingly, the infection rate is lower in males, with $45.8 \%$ and $54.2 \%$ of positive cases, respectively [3], suggesting that gender-related factor may worsen disease evolution and symptoms. In China, the death rate for men was $2.8 \%$, compared to $1.7 \%$ for women, and males represented $73 \%$ of deaths $[4,5]$. A recent review on all the available epidemiological studies, collecting data from 59,254 patients from 11 different countries, has shown an association between male sex and higher mortality rate [6]. These findings suggest the presence of a male-related susceptibility. Therefore, being male is as much a risk factor 


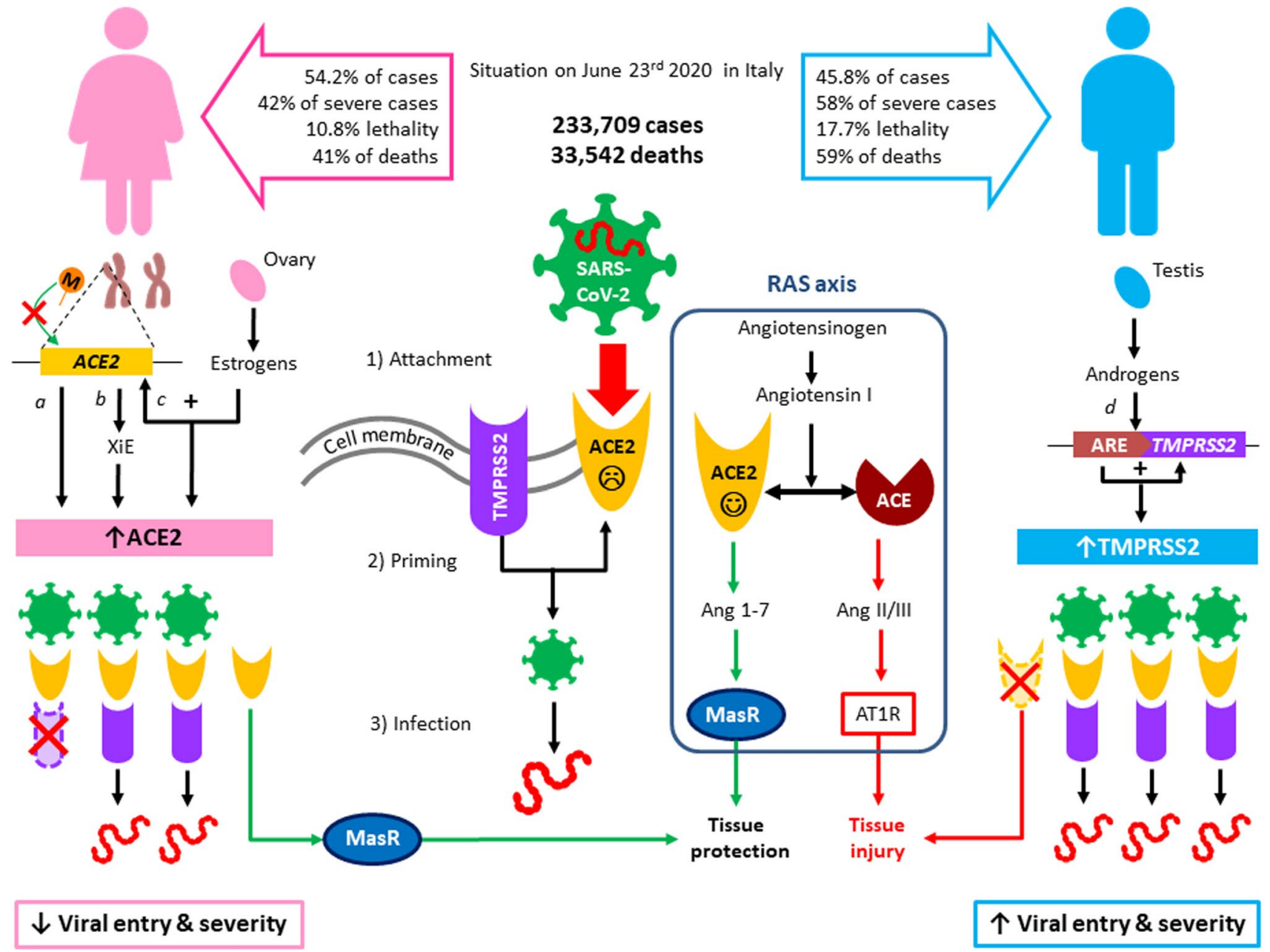

Fig. 1 Proposed mechanisms of sex-related susceptibility to COVID19. On the top of the figure, epidemiological data from the Italian Ministry of Health are reported, with respective gender distribution of cases and deaths. A schematic representation of SARS-CoV-2 mechanism of infection is reported: after binding of viral spike proteins to angiotensin-converting enzyme 2 (ACE2) (1), transmembrane serine protease-2 (TMPRSS2) primes S protein (2), favoring viral entry and infection (3). ACE2 is also crucial in tissue response to viral infection, as it is typically involved in the the renin-angiotensin system (RAS), where it converts angiotensin I into angiotensin 1-7 (Ang 1-7), which binds to Mas receptor (MasR) and favors tissue protection, mainly by hypotensive and anti-inflammatory pathways. Conversely, ACE converts angiotensin I into angiotensin II/III (Ang II/III) that binds to angiotensin II type 1 receptor (AT1R), favoring tissue injury. On the left, the main mechanisms involved in reduced COVID-19 severity and mortality in women are proposed: (a) ACE2 methylation ( $\mathrm{M}$, orange dot) is reduced in women, resulting in higher

for COVID-19 severity and mortality as being old. Several social factors, genetic, immunological, and hormonal differences, as well as lifestyle habits (i.e., smoking and alcohol consumption, chronic diseases, etc.), have been considered to play a role in this gender disparity. Interestingly, men were also disproportionately affected during the SARS and MERS outbreaks, which were caused by other members
ACE2 expression; (b) ACE2 is located on the $\mathrm{X}$ chromosome, which in females is present in two copies, in a region of the short arm where $15-30 \%$ of genes undergoes $\mathrm{X}$ inactivation Escape (XiE); (c) estrogens, produced by the ovary, promote ACE2 expression. Increased levels of ACE2 would provide a larger pool for tissue protection (green arrows) after viral entry. On the right, mechanisms involved in male increased susceptibility: (d) androgens, produced by testes, bind to the androgen receptor and are recognized by androgen-responsive elements (ARE) in the promoter of TMPRSS2, leading to increased expression, which in turn favors viral entry in males, whereas low levels of androgens in women may keep at low levels TMPRSS2 expression, representing a further protective factor for the development of COVID-19 infection. The lack of increased ACE2 pool in men due to low estrogens would favor the ACE pathway (red arrows) in the RAS axis, which further promotes tissue injury and disease severity in men, compared with women with the same viral load

of the family Coronaviridae. More women than men were infected by SARS in Hong Kong in 2003, but the death rate among men was 50\% higher [7]. Although it is assumed that older men have more comorbidities than women of similar age, a tentative hypothesis to explain these epidemiologic findings is the role of the angiotensin-converting enzyme 2 (ACE2): SARS-CoV-2 engages ACE2 in alveolar epithelial 
cells as the entry receptor and employs the serine protease TMPRSS2 for S protein priming [8,9]. ACE2 is a crucial component of the renin-angiotensin system (RAS) (Fig. 1). The classical RAS ACE-Ang II-AT1R regulatory axis and the ACE2-Ang 1-7-MasR counter-regulatory axis play an essential role in maintaining homeostasis in humans. ACE2 is widely distributed in the heart, kidneys, lungs, and testes. ACE2 antagonizes the activation of the classical RAS system and protects against organ damage, protecting against hypertension, diabetes, and cardiovascular disease. Similar to SARS-CoV, SARS-CoV-2 also uses the ACE2 receptor to invade human alveolar epithelial cells. Acute respiratory distress syndrome (ARDS) is a clinical high-mortality disease, and ACE2 has a protective effect on this type of acute lung injury [10, 11]. Interestingly, also in the infection by H5N1, an increase of AngII levels was observed, and they were positively associated with the severity of the disease. Infected mice also showed a downregulation of ACE2 in lungs and an increase of AngII [12]. So far, the binding of COVID-19 spike protein to ACE2 has been shown to downregulate ACE2 and, in turn, to decrease angiotensin 1-7 production. This mechanism may be involved in the pathogenesis of pulmonary hypertension and insufficiency caused by SARS-CoV-2 infection [13]. Therefore, the downregulation of ACE2 expression in SARS-CoV-2 patients may play a causal role in the pathogenesis of COVID-19, as observed in ARDS, SARS-CoV and H5N1, which provides a reasonable explanation for the progression into ARDS.

$A C E 2$ gene expression in nasal epithelium increases with age [14], but gender differences are not consistent [15-17]. Data from animal experiments and clinical investigations suggest that components of RAS are markedly affected by sex hormones [17, 18]. In particular, estrogen modifies the local renin-angiotensin system homeostasis and achieves protective effects in atrial myocardium by increasing ACE2 expression [19]. Since ACE2 is widely present in human alveolar epithelial, we could hypothesize hormonal regulation even in lung tissues. It was previously reported that estrogen is protective against SARS infection in mice [20]. Interestingly, among these regulatory regions, there are many estrogen receptor-binding motifs and a few androgen receptor-binding motifs [21]. While ACE2 expression in high in infants and highest in adolescent and decrease dramatically in adult males, transgender males who underwent estrogen therapy (estradiol) and androgen deprivation therapy (spirolactone) for 1 year show significantly higher ACE2 expression level and more ACE2-expressing cells among testis Sertoli cells [21]. It should be noted, similar to the ACE2 expression decline over age, both estrogen and androgen are well known to decrease with age. Therefore, the prognosis of severely ill patients with COVID-19 may be related to the decrease in ACE2 activity in male patients, particularly those with chronic underlying diseases.
SARS-CoV-2 infection reduces ACE2 activity and receptor consumption, further exacerbating pathophysiological mechanisms, such as Ang II/ACE regulation imbalance. However, this aspect requires further investigations in lung epithelial tissues from COVID-19 patients of both sexes with different severity of the disease.

Interestingly, the gene encoding ACE2 is located on the $\mathrm{X}$ chromosome, which in females is present in two copies. However, although they inherit a maternal X chromosome and a paternal X chromosome, following Lyon theory [22], one of the two $\mathrm{X}$ chromosomes is transcriptionally silenced, and such inactivation mechanism occurs randomly during late blastocyst stage. This complex process of silencing is controlled by two noncoding RNA and results in the condensation of one $\mathrm{X}$ chromosome into a compact structure, referred to as Barr body [23]. The X-inactivation is a fundamental event to ensure a balanced gene expression between sexes; nonetheless, approximately $15-30 \%$ of the genes, most of which localize on the short arm (p) of the X chromosome, can escape the inactivation [24, 25]. Since ACE2 maps at band p22.2, it is likely that it may escape gene inactivation. This phenomenon could hence explain the observed differences in ACE2 expression between sexes [26].

In addition to $\mathrm{X}$ inactivation escape, gene expression of $A C E 2$ could be regulated through an epigenetic mechanism consisting in DNA methylation at the cytosine-phosphateguanine $(C p G)$ sites mediated by DNA methyltransferases [27]. Environmental or endogenous factor can affect DNA methylation levels resulting thus in an altered gene expression. Interestingly, a recent study performed on patients with essential hypertension has found a higher $C p G$ methylation in patients compared to controls; furthermore, they also reported a statistically significant difference in DNA methylation levels between healthy males and healthy females. The latter finding could, hence, further support a sex-related ACE2 gene expression [28].

In conclusion, ACE2 not only provides a pathway for viral infection, but also represents a protective factor in the severity of the disease. This double-faced role could seem in contrast with epidemiological data. A possible explanation is that the binding of SARS-CoV-2 to ACE2 leads to a rapid saturation of the latter and a disequilibrium of RAS axis in lungs, leading to multi-organ inflammation due to the prevalence of the AT1 pathway. Therefore, under the same viral load in the two sexes, we could hypothesize a more rapid saturation of ACE2 in men than in women, who present a larger pool of ACE2 thanks to hormonal and genetic features, representing a protective factor in the onset of the disease (Fig. 1).

Interestingly, ACE2 is highly expressed also in the testis [29]. On this basis, recent hypotheses suggested that the testis could represent a viral reservoir and may play a role in viral persistence in males. However, this hypothesis is 
unlikely and, in the only study available to date, SARSCoV-2 was not detected in testicular biopsies and seminal fluid [30, 31]. Moreover, SARS-CoV-2 could reach the testis only by blood, but to date evidence of serum viral load is still controversial [32-34]. The presence of SARS-CoV-2 in the testis and seminal fluid clearly needs further investigations and could have important clinical implications in our understanding of viral infection and transmission [35]. Data derived from other SARS-CoV infections suggest that in patients recovered from COVID-19, especially for those in reproductive age, andrological consultation and evaluation of gonadal function including semen analysis should be suggested [36].

As previously reported, SARS-CoV-2, as well as other coronaviruses and influenza viruses, critically depends on TMPRSS2 for viral entry and spread in the host $[8,37,38]$, highlighting the central and conserved role of TMPRSS2 in the pathogenesis of viral-related diseases. However, the expression of this protein is very low in the testis [39], making viral accumulation in male gonads unlikely.

A more promising hypothesis to explain gender differences of COVID-19 severity rather relies on the role of sex hormones, as previously demonstrated for ACE2. This hypothesis also applies to TMPRSS2, which was first identified in prostate cancer cells, where it is strongly upregulated in response to androgens [40]. In fact, the androgen-responsive element is the only known transcription promoter for the TMPRSS2 gene and this has been strongly associated with the acquired tumor growth and invasiveness of prostate cancer, particularly when TMPRSS2-ERG gene fusion is observed (Reviewed in [41]) and suppressing circulating androgens in men might reduce its activity and reduce the severity of COVID infection [42]. Immunohistochemistry studies, although with limited sample size, suggest that the TMPRSS 2 protein is more heavily expressed in bronchial epithelial cells than in surfactant-producing type II alveolar cells and alveolar macrophages, and that there is no expression in type I alveolar cells that form the respiratory surface [43]; however, there is no evidence of sex difference in TMPSSR 2 mRNA levels in the lung [39]. Understanding how TMPRSS2 protein expression in the lung varies could reveal important insights into differential susceptibility to coronavirus infections. Low levels of androgens in women may keep at low levels TMPRSS2 protein expression, representing a further protective factor for the development of COVID-19 infection (Fig. 1). However, it should be recognized that the gap between genders starts being evident after the fifth to sixth decade when, notoriously, serum testosterone declines in men. Accordingly, a recent study has shown that low testosterone represents a predictor of poor prognosis in SARS-CoV-2-infected men [44]. It is tempting to speculate that anti-androgenic therapies used in the treatment of prostate cancer patients might reduce susceptibility to COVID-19 pulmonary symptoms and mortality by reducing testosterone levels and TMPRSS2 activity, but the multifactorial nature of COVID-19 infection and hormonal regulation in men does not allow to draw any definitive conclusion. Given its central role in initiating SARS-CoV-2 infection, factors modulating TMPRSS2 expression or activity could represent a promising candidate for potential interventions against COVID-19 and could add further knowledge on the double-edged role of ACE2 as both an infection-promoting factor and a disease-protective agent.

\section{Conclusions}

Altogether, available evidence points toward two not-mutually exclusive mechanisms in differential gender susceptibility to COVID-19 by sex hormonal regulation of the two main actors in SARS-CoV-2 infection: ACE2 and TMPRSS2. On one hand, ACE2 expression could be increased in women, either by estrogens or constitutively by skewed X chromosome inactivation, providing a larger reservoir of ACE2 to maintain the fundamental equilibrium of RAS-regulatory axis after viral infection on a multi-organ level. On the other hand, low levels of androgens in women may keep at low levels TMPRSS2 expression, representing a further protective factor for the development of COVID-19 infection. Both mechanisms consistently point to the role of sex hormones and chromosomes in the differential severity of SAR-CoV2 infection between sexes, thus representing a one-way avenue to the increased susceptibility to COVID-19 in men. These aspects are worthy of further investigations regarding the epidemiological and biological aspects of this different susceptibility and lethality between sexes. Finally, other genderrelated risk factors should be taken into account, such as higher rates of hypertension, smoking, and coronary artery disease that are more predominant in men than women. Altogether, these aspects point toward the man as the true weak sex in COVID-19 challenge.

Acknowledgments Open access funding provided by Universit $\tilde{A}$ degli Studi di Padova within the CRUI-CARE Agreement.

Funding Fondazione CaRiPaRo to DIMED, University of Padova"Immunoinfiammazione e coinvolgimento multiorgano in Covid 19-CoviDIMED”.

\section{Compliance with ethical standards}

Conflict of interest The authors have declared that no conflict of interest exists.

Research involving human participants and/or animals Human partecipants and/or animals are not used for this study. 
Informed consent Informed consent is not required.

Open Access This article is licensed under a Creative Commons Attribution 4.0 International License, which permits use, sharing, adaptation, distribution and reproduction in any medium or format, as long as you give appropriate credit to the original author(s) and the source, provide a link to the Creative Commons licence, and indicate if changes were made. The images or other third party material in this article are included in the article's Creative Commons licence, unless indicated otherwise in a credit line to the material. If material is not included in the article's Creative Commons licence and your intended use is not permitted by statutory regulation or exceeds the permitted use, you will need to obtain permission directly from the copyright holder. To view a copy of this licence, visit http://creativecommons.org/licenses/by/4.0/.

\section{References}

1. Guan WJ, Ni ZY, Hu Y et al (2020) Clinical characteristics of coronavirus disease 2019 in China. N Engl J Med. https://doi. org/10.1056/NEJMoa2002032[published online ahead of print, 2020 Feb 28]

2. Italian Ministry of Health (2020) Covid-19, situation report update at 23 June 2020. http://www.salute.gov.it/portale/news/ p3_2_1_1_1.jsp?lingua $=$ italiano $\&$ menu $=$ notizie $\& \mathrm{p}=$ dalministe ro\&id $=4228$. Accessed 24 June 2020

3. Italian Ministry of Health (2020) https://www.epicentro.iss.it/ coronavirus/bollettino/Bollettino-sorveglianza-integrata-COVID -19_23-giugno-2020.pdf. Accessed 24 June 2020

4. The Novel Coronavirus Pneumonia Emergency Response Epidemiology Team (2020) The epidemiological characteristics of an outbreak of 2019 novel coronavirus diseases (COVID-19) China, 2020. China CDC Wky 2(8):113-122

5. Chen T, Wu D, Chen H et al (2020) Clinical characteristics of 113 deceased patients with coronavirus disease 2019: retrospective study. BMJ 368:m1091. https://doi.org/10.1136/bmj.m1091 (Published 2020 Mar 26; published correction appears in BMJ. 2020 Mar 31;368:m1295)

6. Borges-do-Nascimento IJ, Cacic N, Abdulazeem HM et al (2020) Novel coronavirus infection (COVID-19) in humans: a scoping review and meta-analysis. J Clin Med. 9(4):E941. https://doi. org/10.3390/jcm9040941 (Published 2020 Mar 30)

7. Choi KW, Chau TN, Tsang O et al (2003) Outcomes and prognostic factors in 267 patients with severe acute respiratory syndrome in Hong Kong. Ann Intern Med 139(9):715-723. https:// doi.org/10.7326/0003-4819-139-9-200311040-00005

8. Hoffmann M, Kleine-Weber H, Schroeder S et al (2020) SARSCoV-2 cell entry depends on ACE2 and TMPRSS 2 and is blocked by a clinically proven protease inhibitor. Cell 181(2):271-280.e8. https://doi.org/10.1016/j.cell.2020.02.052

9. Zhou P, Yang XL, Wang XG et al (2020) A pneumonia outbreak associated with a new coronavirus of probable bat origin. Nature 579(7798):270-273. https://doi.org/10.1038/s41586-020-2012-7

10. Li W, Moore MJ, Vasilieva N et al (2003) Angiotensin-converting enzyme 2 is a functional receptor for the SARS coronavirus. Nature 426(6965):450-454. https://doi.org/10.1038/nature02145

11. Imai Y, Kuba K, Rao S et al (2005) Angiotensin-converting enzyme 2 protects from severe acute lung failure. Nature 436(7047):112-116. https://doi.org/10.1038/nature03712

12. Zou Z, Yan Y, Shu Y et al (2014) Angiotensin-converting enzyme 2 protects from lethal avian influenza A H5N1 infections. Nat Commun. 5:3594. https://doi.org/10.1038/ncomms4594 (Published 2014 May 6)
13. Gurwitz D (2020) Angiotensin receptor blockers as tentative SARS-CoV-2 therapeutics. Drug Dev Res. https://doi. org/10.1002/ddr.21656 (published online ahead of print, 2020 Mar 4)

14. Bunyavanich S, Do A, Vicencio A (2020) Nasal gene expression of angiotensin-converting enzyme 2 in children and adults. JAMA. https://doi.org/10.1001/jama.2020.8707

15. Xie X, Chen J, Wang X, Zhang F, Liu Y (2006) Age- and gender-related difference of ACE2 expression in rat lung. Life Sci. 78(19):2166-2171. https://doi.org/10.1016/j.lfs.2005.09.038 (published correction appears in Life Sci. 2006 Nov 25;79(26):2499. Xudong, Xie [corrected to Xie, Xudong]; Junzhu, Chen [corrected to Chen, Junzhu]; Xingxiang, Wang [corrected to Wang, Xingxiang]; Furong, Zhang [corrected to Zhang, Furong]; Yanrong, Liu [corrected to Liu, Yanrong])

16. Soro-Paavonen A, Gordin D, Forsblom C et al (2012) Circulating ACE2 activity is increased in patients with type 1 diabetes and vascular complications. J Hypertens 30(2):375-383. https://doi. org/10.1097/HJH.0b013e32834f04b6

17. Dalpiaz PL, Lamas AZ, Caliman IF et al (2015) Sex hormones promote opposite effects on ACE and ACE2 activity, hypertrophy and cardiac contractility in spontaneously hypertensive rats. PLoS ONE 10(5):e0127515. https://doi.org/10.1371/journal.pone.01275 15 (Published 2015 May 26; published correction appears in PLoS One. 2015;10(7):e0133225)

18. Gupte M, Thatcher SE, Boustany-Kari CM et al (2012) Angiotensin converting enzyme 2 contributes to sex differences in the development of obesity hypertension in C57BL/6 mice. Arterioscler Thromb Vasc Biol 32(6):1392-1399. https://doi.org/10.1161/ ATVBAHA.112.248559

19. Bukowska A, Spiller L, Wolke C et al (2017) Protective regulation of the ACE2/ACE gene expression by estrogen in human atrial tissue from elderly men. Exp Biol Med (Maywood) 242(14):14121423. https://doi.org/10.1177/1535370217718808

20. Channappanavar R, Fett C, Mack M, Ten Eyck PP, Meyerholz DK, Perlman S (2017) Sex-based differences in susceptibility to severe acute respiratory syndrome coronavirus infection. J Immunol 198:4046-4053. https://doi.org/10.4049/jimmunol.1601896

21. Chen J, Jiang Q, Xia X et al (2020) Individual variation of the SARS-CoV-2 receptor ACE2 gene expression and regulation. Aging Cell. https://doi.org/10.1111/acel.13168 (published online ahead of print, $2020 \mathrm{Jun} 19)$

22. Lyon MF (1961) Gene action in the X-chromosome of the mouse (Mus musculus L.). Nature 190:372-373. https://doi. org/10.1038/190372a0

23. Boumil RM, Lee JT (2001) Forty years of decoding the silence in X-chromosome inactivation. Hum Mol Genet 10(20):2225-2232. https://doi.org/10.1093/hmg/10.20.2225

24. Berletch JB, Yang F, Xu J, Carrel L, Disteche CM (2011) Genes that escape from X inactivation. Hum Genet 130(2):237-245. https://doi.org/10.1007/s00439-011-1011-z

25. Posynick BJ, Brown CJ (2019) Escape from X-chromosome inactivation: an evolutionary perspective. Front Cell Dev Biol. 7:241. https://doi.org/10.3389/fcell.2019.00241 (Published 2019 Oct 22)

26. Tukiainen T, Villani AC, Yen A et al (2017) Landscape of $\mathrm{X}$ chromosome inactivation across human tissues. Nature 550(7675):244-248. https://doi.org/10.1038/nature24265

27. Razin A, Szyf M (1984) DNA methylation patterns formation and function. Biochim Biophys Acta 782(4):331-342. https://doi. org/10.1016/0167-4781(84)90043-5

28. Fan R, Mao SQ, Gu TL et al (2017) Preliminary analysis of the association between methylation of the ACE2 promoter and essential hypertension. Mol Med Rep 15(6):3905-3911. https://doi. org/10.3892/mmr.2017.6460 
29. Douglas GC, O’Bryan MK, Hedger MP et al (2004) The novel angiotensin-converting enzyme (ACE) homolog, ACE2, is selectively expressed by adult Leydig cells of the testis. Endocrinology 145(10):4703-4711. https://doi.org/10.1210/en.2004-0443

30. Song C, Wang Y, Li W et al (2020) Absence of 2019 novel coronavirus in semen and testes of COVID-19 patients. Biol Reprod. https://doi.org/10.1093/biolre/ioaa050 (published online ahead of print, 2020 Apr 16)

31. Paoli D, Pallotti F, Colangelo $S$ et al (2020) Study of SARS-CoV-2 in semen and urine samples of a volunteer with positive nasopharyngeal swab. J Endocrinol Invest. https://doi.org/10.1007/ s40618-020-01261-1 (published online ahead of print, 2020 Apr 23)

32. Ling Y, Xu SB, Lin YX et al (2020) Persistence and clearance of viral RNA in 2019 novel coronavirus disease rehabilitation patients. Chin Med J (Engl). https://doi.org/10.1097/CM9.00000 00000000774 (published online ahead of print, 2020 Feb 28)

33. Xie C, Jiang L, Huang $\mathrm{G}$ et al (2020) Comparison of different samples for 2019 novel coronavirus detection by nucleic acid amplification tests. Int J Infect Dis 93:264-267. https://doi.org/10.1016/j. ijid.2020.02.050 (published online ahead of print, 2020 Feb 27)

34. Zheng S, Fan J, Yu F et al (2020) Viral load dynamics and disease severity in patients infected with SARS-CoV-2 in Zhejiang province, China, January-March 2020: retrospective cohort study. BMJ 369:M1443. https://doi.org/10.1136/bmj.m1443 (Published 2020 Apr 21)

35. Paoli D, Pallotti F, Turriziani O et al (2020) SARS-CoV-2 presence in seminal fluid: myth or reality. Andrology. https://doi. org/10.1111/andr.12825 (published online ahead of print, 2020 May 26)

36. Corona G, Baldi E, Isidori AM et al (2020) SARS-CoV-2 infection, male fertility and sperm cryopreservation: a position statement of the Italian Society of Andrology and Sexual Medicine (SIAMS) (Società Italiana di Andrologia e Medicina della Sessualità). J Endocrinol Invest. https://doi.org/10.1007/s40618-02001290-w (published online ahead of print, 2020 May 27)

37. Chaipan C, Kobasa D, Bertram S et al (2009) Proteolytic activation of the 1918 influenza virus hemagglutinin. J Virol 83(7):3200-3211. https://doi.org/10.1128/JVI.02205-08
38. Matsuyama S, Nagata N, Shirato K, Kawase M, Takeda M, Taguchi F (2010) Efficient activation of the severe acute respiratory syndrome coronavirus spike protein by the transmembrane protease TMPRSS2. J Virol 84(24):12658-12664. https://doi. org/10.1128/JVI.01542-10

39. Stopsack KH, Mucci LA, Antonarakis ES, Nelson PS, Kantoff PW (2020) TMPRSS2 and COVID-19: serendipity or opportunity for intervention? Cancer Discov. https://doi.org/10.1158/2159-8290. CD-20-0451 (published online ahead of print, 2020 Apr 10)

40. Lin B, Ferguson C, White JT et al (1999) Prostate-localized and androgen-regulated expression of the membrane-bound serine protease TMPRSS2. Cancer Res 59(17):4180-4184

41. De Toni L, Garolla A, Di Nisio A, Rocca MS, Foresta C (2020) Caution in the management of SARS-CoV-2 infection in males. Andrology. https://doi.org/10.1111/andr.12829

42. Montopoli M, Zumerle S, Vettor R et al (2020) Androgen-deprivation therapies for prostate cancer and risk of infection by SARSCoV-2: a population-based study $(n=4532)$. Ann Oncol S09237534(20):39797. https://doi.org/10.1016/j.annonc.2020.04.479

43. Bertram S, Heurich A, Lavender $H$ et al (2012) Influenza and SARS-coronavirus activating proteases TMPRSS2 and HAT are expressed at multiple sites in human respiratory and gastrointestinal tracts. PLoS ONE 7(4):e35876. https://doi.org/10.1371/journ al.pone. 0035876

44. Rastrelli G, Di Stasi V, Inglese F et al (2020) Low testosterone levels predict clinical adverse outcomes in SARS-CoV-2 pneumonia patients. Andrology. https://doi.org/10.1111/andr.12821 (published online ahead of print, 2020 May 20)

Publisher's Note Springer Nature remains neutral with regard to jurisdictional claims in published maps and institutional affiliations. 